\title{
VIEWPOINT
}

\section{What Medicine Can Teach Law Enforcement}

\author{
Kimberly M. Tartaglia, MD \\ Department of Medicine, Ohio State University College of Medicine Columbus, OH, USA.
}

J Gen Intern Med 36(5):1415

DOI: $10.1007 / \mathrm{s} 11606-020-06033-4$

(C) Society of General Internal Medicine 2020

A s a physician, I am not trained in law enforcement and cannot speak to its rules or culture. But I do know medicine. I know medicine is a field, like many others, where altruistic people train hard to serve and heal others. I imagine that police officers do the same; they train hard to protect others.

But medicine is far from perfect. Since the late 1990s, in part due to reports from the Institute of Medicine, it has become increasingly clear that despite good intentions, the medical community was making errors, hurting patients, and even killing them at times ${ }^{1}$. They were doing the opposite of what they set out to do.

Over the last 20 years, the medical community has been trying to come to grips with their failures ${ }^{2}$. Nurses, pharmacists, physicians, and administrative staff have learned principles of patient safety and of quality improvement. But knowledge of those principles is insufficient to affect change, because as the popular saying goes "culture eats strategy for breakfast." 3

Similar to concerns about patient safety, the medical community has had to grapple with issues such as toxic hierarchies and bias. Examples of explicit and implicit bias, towards patients, trainees, staff, and faculty, are not hard to find. In fact, ask any person of color or woman if they have experienced bias in a medical interaction, either as a patient or as a professional. Medical centers have had to make a targeted effort to address biases at all levels, from admissions committees at medical colleges to individual physicians and nurses.

Have there been reports of inappropriate, even criminal activity, among physicians, pharmacists, and nurses? Absolutely. Is that common? No way. Yet, we still know that patients are harmed in hospitals and medical offices around the country. That's because in $99 \%$ of cases, the issue is a system problem. Thus, we need systemic solutions.

So, back to police officers and law enforcement. As justice for George Floyd and other victims continues to move forward, let us not only examine the individuals who committed the crimes against them. Let us also critically scrutinize the system that allows this to happen and allows this to continue. Let us examine why we do not have police officers that look like the communities they serve. Let us reflect on why officers are trained in "killology" and why "shoot first, investigate later" seems to be a much too common scenario in the USA $^{4}$. Let us ask what skills law enforcement officers need to do their job well while protecting the people it intends to serve. Let us examine what a "just culture" looks like for law enforcement ${ }^{5}$.

Within medicine, for more than 10 years, I've worked to be a safety advocate for my patients and the healthcare system. I call on physicians and the public to embrace the role of safety advocate for \#BlackLivesMatter and to pressure law enforcement to fix the system and embrace their role as a safety advocate for the public they serve.

Corresponding Author: Kimberly M. Tartaglia, MD; Department of Medicine, Ohio State University College of Medicine Columbus, $\mathrm{OH}$, USA (e-mail: Kimberly.Tartaglia@osumc.edu).

\section{Compliance with Ethical Standards:}

Conflict of Interest: The author declares that she does not have a conflict of interest.

\section{REFERENCES}

1. Institute of Medicine (US) Committee on Quality of Health Care in America, Kohn LT, Corrigan JM, Donaldson MS, eds. To Err is Human: Building a Safer Health System. Washington (DC): National Academies Press (US); 2000.

2. Chassin MR. Improving the quality of health care: what's taking so long? Health Aff (Millwood). 2013;32(10):1761-1765. https://doi.org/10.1377/ hlthaff.2013.0809

3. Weaver SJ, Lubomksi LH, Wilson RF, Pfoh ER, Martinez KA, Dy SM Promoting a culture of safety as a patient safety strategy: a systematic review. Ann Intern Med. 2013;158(5 Pt 2):369-374. https://doi.org/10. 7326/0003-4819-158-5-201303051-00002

4. Grossman, D. Killology. Website: https://www.killology.com/, accessed June 9, 2020.

5. Boysen PG 2nd. Just culture: a foundation for balanced accountability and patient safety. Ochsner J. 2013;13(3):400-406.

Publisher's Note: Springer Nature remains neutral with regard to jurisdictional claims in published maps and institutional affiliations. 